\title{
NUEVOS DATOS SOBRE EL CALCOLÍTICO DE EXTREMADURA: EL YACIMIENTO DE LA SIERRECILLA (SANTA AMALIA, BADAJOZ)
}

\author{
NEW EVIDENCE ABOUT COPPER AGE EXTREMADURA: \\ THE SITE OF LA SIERRECILLA (SANTA AMALIA, BADAJOZ)
}

\author{
MARÍA CRUZ BERROCAL* \\ ENRIQUE CERRILLO CUENCA** \\ JOSE ANTONIO GARCÍA SOLANO***
}

Resumen: Se presentan los resultados de la excavación realizada en el yacimiento de La Sierrecilla (Santa Amalia, Badajoz), que indican que se trata de un asentamiento del III milenio BC. Esta adscripción se sostiene sobre los materiales documentados, particularmente cerámicos. Es destacable la presencia de elementos relacionados con la metalurgia.

Palabras clave: cuenca del Guadiana, calcolítico, asentamiento.
Abstract: This paper presents the results of the excavations carried out in the site of La Sierrecilla (Santa Amalia, Badajoz province), which show this was a settlement from the 3rd millenium BC. This assumption lies mostly on the pottery evidence. The presence of elements related to the metallurgical process is also relevant.

Key words: Guadiana basin, calcolithic, settlement.

\section{INTRODUCCIÓN}

La investigación sobre el Calcolítico en Extremadura tiene dos vertientes muy importantes, producto del incremento de la actividad arqueológica en Extremadura en las dos últimas décadas -que incluye la excavación de asentamientos de cierta entidad-: por un lado, la intensidad del poblamiento documentado tanto en la cuenca del Tajo como en la del Guadiana; por el otro, el aceptable grado de conocimiento que se ha alcanzado en los yacimientos excavados. En este crecimiento es

\footnotetext{
* Grupo de Investigación en Prehistoria Social y Económica, Insti-
uto de Historia, CSIC, Madrid. Correo electrónico mariacb@ih.csic.es.

* Grupo de Investigación en Prehistoria Social y Económica, Insti-
tuto de Historia, CSIC, Madrid. Correo electrónico mariacb@ih.csic.es.

** Instituto de Arqueología de Mérida, CSIC, Mérida (Badajoz). Correo electrónico ecerrillo@iam.csic.es. *** Instituto Geológico y Minero. Ríos Rosas 23, 28003, Madrid. Correo electrónico jg.solano@igme.es.
} (1) Correo electrónico jgsolano@igme.es. significativa la influencia de nuevas propuestas interpretativas del Calcolítico extremeño que conceden un papel relevante a los procesos sociales ocurridos durante el III milenio BC, y reconocen la complejidad y diversidad de entornos y situaciones (Hurtado $1995 \mathrm{y}$ 2003; Enríquez 1995; Bueno et alii 2002-2003).

En contraste con esta relativa abundancia de datos, los intentos de explicación de los inicios de la metalurgia prehistórica en Extremadura (Gómez et alii 1998; Hurtado y Hunt 1999) han enfrentado de forma recurrente el problema de la carestía de evidencias arqueológicas para documentar los procesos de transformación metalúrgica (Hurtado y Hunt 1999: 265). Las primeras producciones de cobre en el actual territorio extremeño únicamente han podido ser abordadas a partir de los propios productos metálicos (Gómez et alii 1998). Faltan por documentar, casi por completo, aspectos relevantes de esta actividad como la explotación 


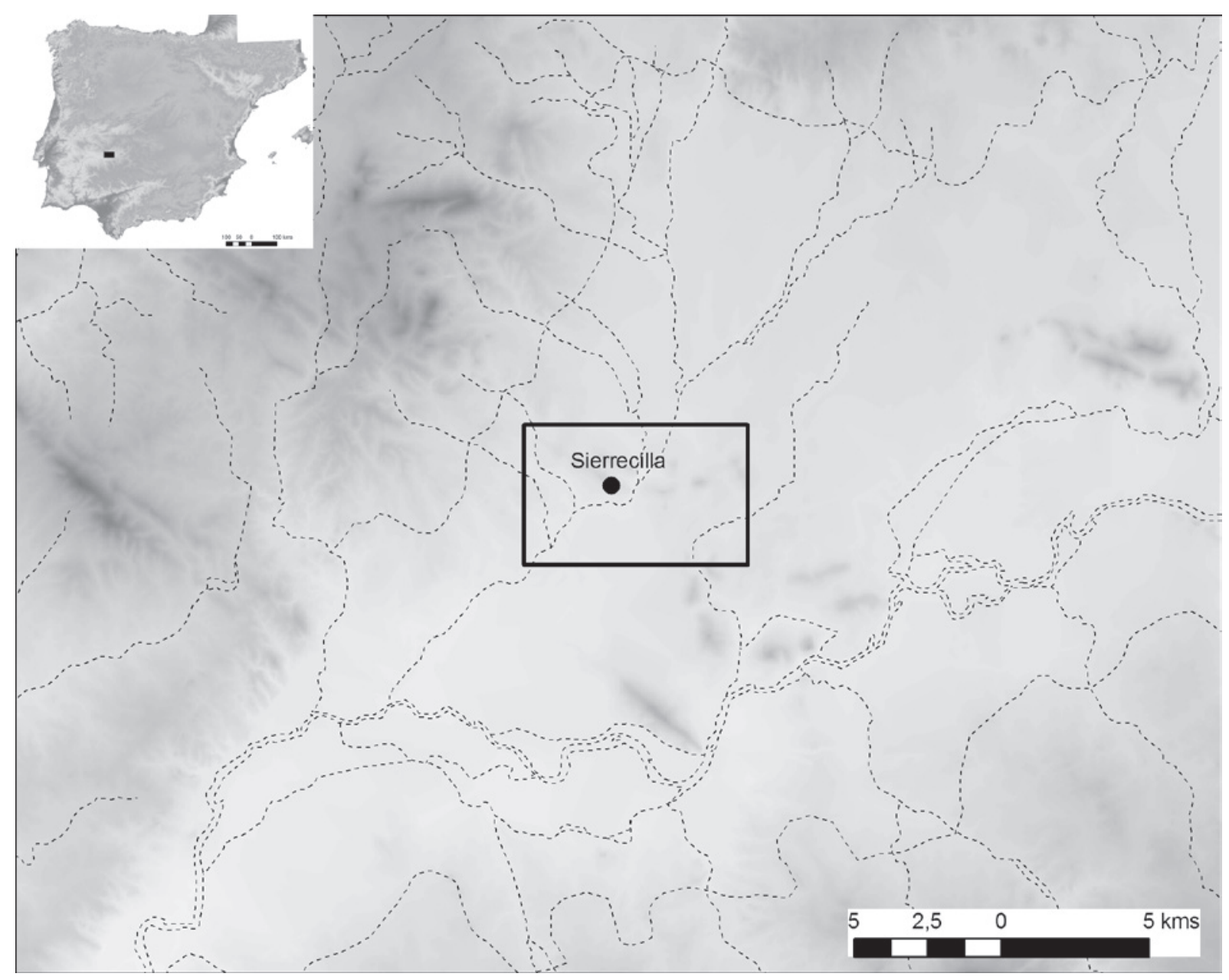

Figura 1: Situación general.

de filones, la identificación de espacios destinados a ella en el interior de los hábitats, o incluso artefactos relacionados con el proceso de fundición (crisoles, toberas, etc.). Por tanto es preciso articular la producción metalúrgica en su contexto espacial, tanto a nivel territorial como microespacial, pero también definir mejor el proceso técnico involucrado.

Algunas de estas evidencias de producción metalúrgica son precisamente las que la excavación de La Sierrecilla (Santa Amalia, Badajoz) ha aportado al conocimiento del trabajo del cobre durante el Calcolítico en este sector del Guadiana, próximo a Mérida (figura 1). Este territorio ha sido objeto de otros trabajos de campo (Enríquez 1990 y 2002; Heras y Cerrillo 2006), que han puesto de relieve, con cierto nivel de detalle, la dinámica de la ocupación desde finales del IV y a lo largo del III milenio cal BC, y permiten contextualizar los resultados obtenidos en La Sierrecilla dentro de un poblamiento homogéneo de estas zonas de vega, en principio centrado en la explotación de recursos agrícolas.

Así, la cuestión que más interesa señalar en este trabajo es que la producción metalúrgica en el Guadiana ha de entenderse dentro de una situación general de intensificación económica que se observa desde el comienzo del III milenio, en momentos aparentemente previos a los primeros contextos campaniformes, estimación cronológica que se suponía más adecuada para la metalurgia extremeña (Gómez et alii 1998: 97).

La Sierrecilla, fuera ya de los terrenos aluvionares de la margen del Guadiana, se sitúa en el cerro del mismo nombre ${ }^{1}$ (figura 2). Fue dado a conocer a la

1. Término municipal de Santa Amalia. Coordenadas: 756850 , 4323600 (huso 29); altitud: 293 m. Hoja 12-30, mapa 1:50000. Cartografía Militar de España. Servicio Geográfico del Ejército. 


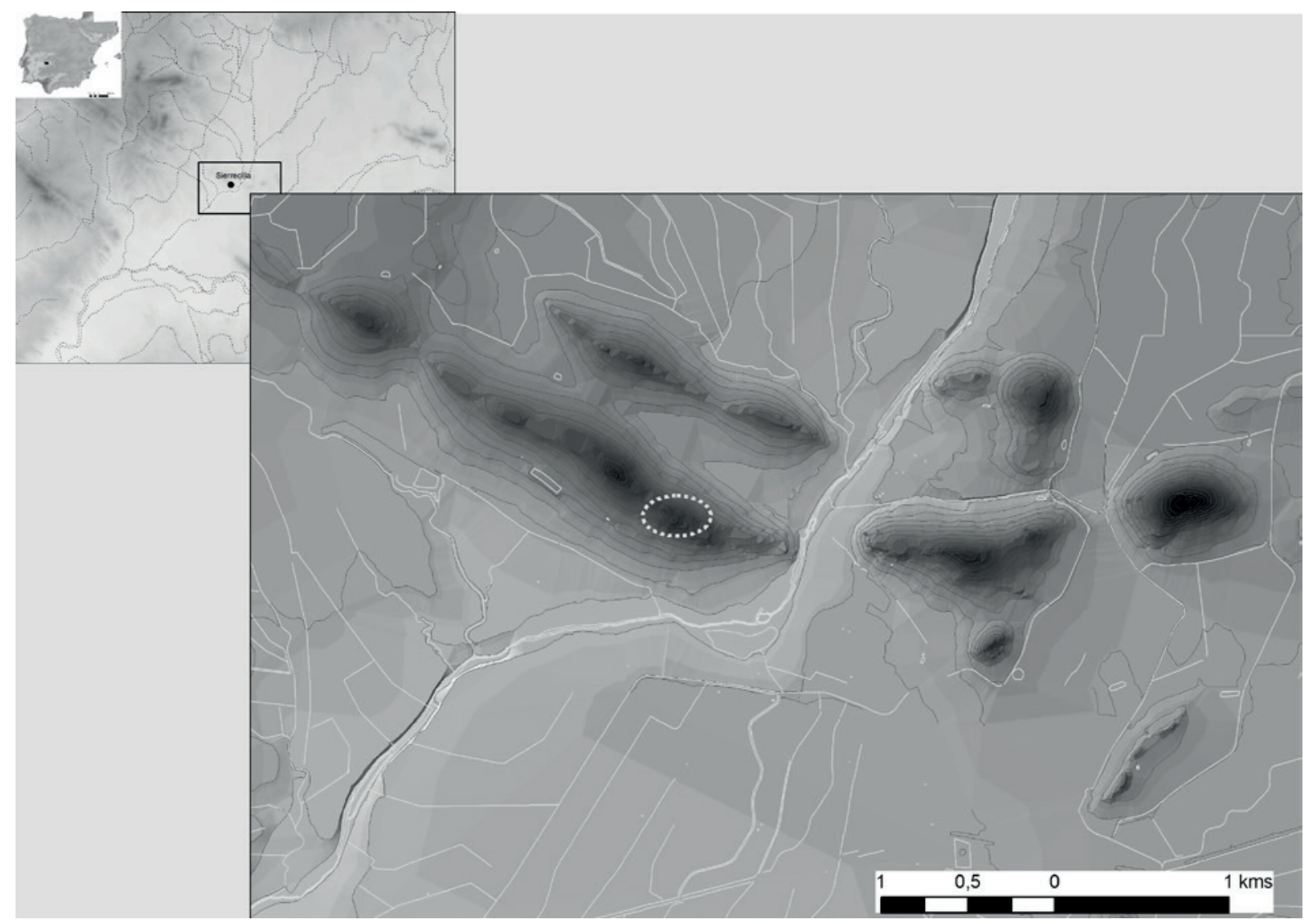

Figura 2: Topografía de la zona.

Dirección General de Patrimonio Cultural de la Junta de Extremadura en julio de 2005 por Eduardo Moreno García, después de que se iniciaran obras promovidas por el ayuntamiento de Santa Amalia en colaboración con la Confederación Hidrográfica del Guadiana para acondicionar el lugar, donde se erige la ermita de San Isidro, como lugar de recreo. En concreto fue decisiva la apertura de una zanja en sentido E-O, que luego se denominó zanja 1 , cubriendo la práctica totalidad de la parte alta del cerro.

Los técnicos de la Dirección General de Patrimonio solicitaron la imposición de un programa de vigilancia arqueológica para la continuación de las obras. La intervención se realizó entre el 19 de julio y el 24 de agosto de 2005. Consistió en seguimiento de zanjas y una pequeña excavación para evaluar el potencial del yacimiento y el daño producido por la zanja $1^{2}$.

2. Dirección: María Cruz Berrocal. Equipo de excavación: Pablo Gallego Casillas, Jose María Ramos López, Manuel Barroso Carrasco y Jose Luis Pérez Paredes. Documentación topográfica: Miguel Angel Rodríguez de Arellano y Francisco Gallego Velarde (Tragsa).
Estas intervenciones (figura 3) han permitido delimitar un área de yacimiento de aproximadamente unos 100 x $90 \mathrm{~m}$, en la zona alta amesetada del cerro. En esta zona hay una hondonada en el centro, de la que existen informaciones contradictorias sobre su carácter artificial (rebajado a propósito) o natural (sedimento arrastrado por el agua). La construcción de la ermita, en 1947, marcó probablemente el momento en el que el cerro empezó a ser visitado con asiduidad y alterado. Todo parece indicar que fue entonces cuando se allanó toda la meseta, pero no existen documentos sobre la construcción o sobre los procesos de remoción de tierras que conllevó ${ }^{3}$ En general al menos todo

3. La información que hemos recopilado procede de los vecinos de Santa Amalia Manuel Agustín Ramos Chaves y Emiliano Nieto Ruiz, y del concejal de obras Valentín González Jiménez. Este último tiene constancia de que el lado $\mathrm{S}$ del cerro fue vaciado de piedra para los pueblos nuevos pacenses, levantados en los años 60 y 70 . Este vacío fue rellenado, después de 1975, por el ayuntamiento, con escombros del pueblo. Además se rellenó también la ladera y la parte alta del cerro, para ampliar la meseta y hacerla más propicia para la estancia. La zona $\mathrm{N}$ del cerro no fue rellenada en esta época, pero su 


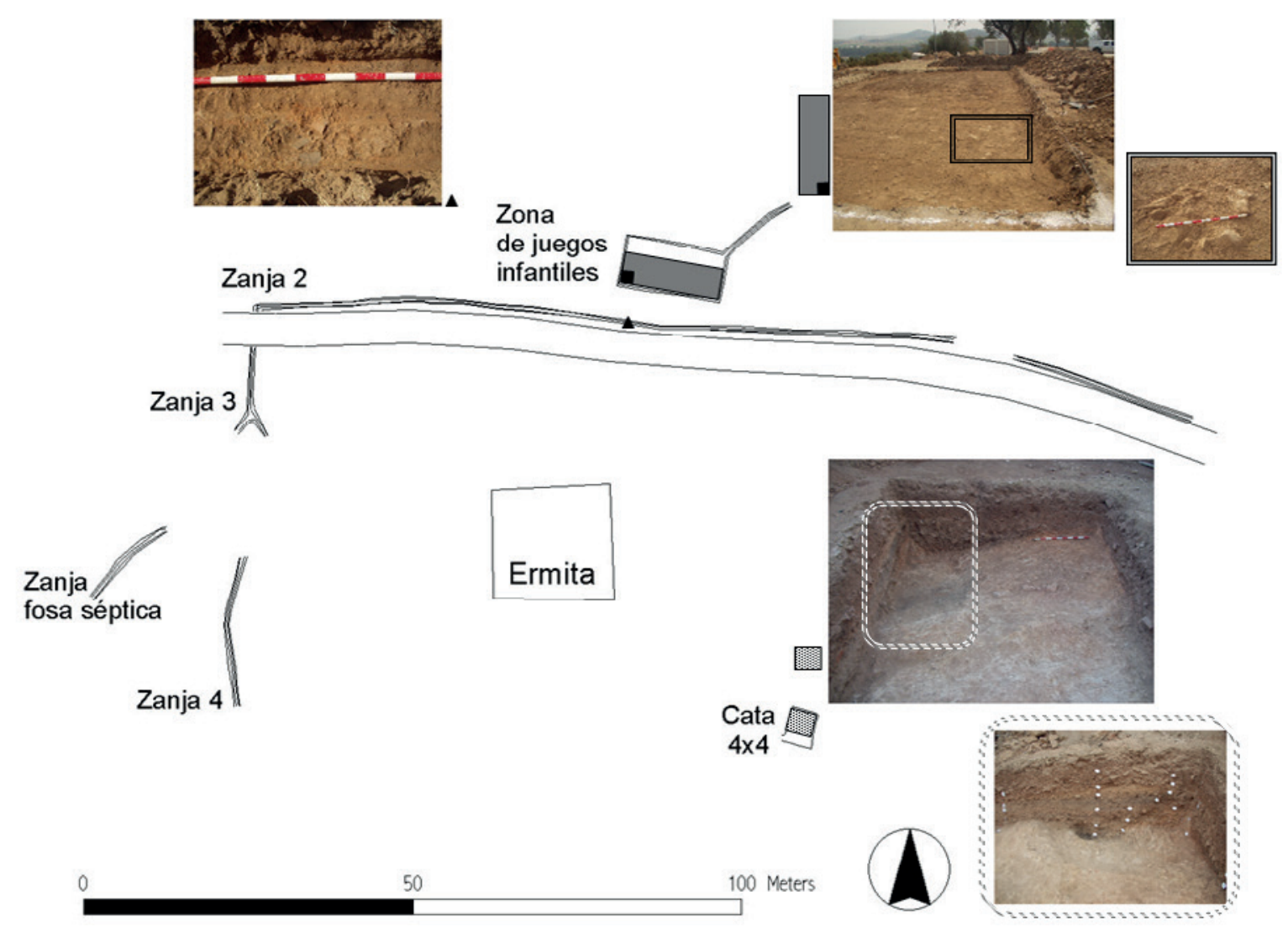

Figura 3. Plano con las intervenciones realizadas en el yacimiento.

el nivel superficial del cerro parece estar removido, ya que los estratos superficiales de todas las áreas intervenidas son similares.

\section{INTERVENCIONES}

Las intervenciones se desarrollaron en siete áreas: seis seguimientos y una excavación. Además se prospectó el cerro sin resultados en cuanto a material de superficie ni manifestaciones de arte rupestre. A continuación se comentará la intervención de cada área, por orden cronológico de realización.

ZANJA 2: trazado E-O, aproximadamente $145 \mathrm{~m}$ de largo por $60-80 \mathrm{~cm}$ de ancho. La profundidad varía entre los 40-50 cm del principio, los 20-30 cm de la zona que más afectaba al yacimiento, y los aproximadamente

aspecto también invita a pensar en un relleno, quizá anterior, contemporáneo al momento de construcción de la ermita.
$40 \mathrm{~cm}$ de su parte final, donde ya no se detectaban restos arqueológicos. Toda la zona podría estar alterada por la presencia de una carretera que cruza el cerro, paralela a la zanja, y por zanjas para cableado eléctrico anteriores (de las que no hay documentación en el ayuntamiento), transversales a la carretera y a la zanja 2 .

Se determinó la existencia de dos niveles: el primero de relleno (ue 1) de tierra suelta, con piedras grandes sueltas y el segundo arqueológico (ue 2) de tierra marrón clara, más compacto, del que se documentó solamente una media de $10 \mathrm{~cm}$. Tiene abundante cerámica. En horizontal se detectaron cambios a lo largo de la zanja. Los más significativos están en el tercio inicial, con una alineación de piedras grandes aflorando en la ue 2 y un tercer estrato más arcilloso también con cerámica. A la altura de la ermita aparecen acumulaciones significativas de piedras planas grandes. Es el tramo que "corta" el montículo sobre el cual está la ermita. No es posible evaluar la posibilidad de que estas piedras estuvieran formando parte de estructuras. 
Por último, a partir de aproximadamente los 100 metros desde el extremo $\mathrm{O}$, desaparece la cerámica, incluso antes de que cambie el relleno. Éste cambia abruptamente algo más abajo, a aproximadamente 115 metros: se convierte en un relleno de piedra desmenuzada $\mathrm{y}$, por último, de arena, posiblemente de una antigua zanja de cableado que en esta parte seguía prácticamente el mismo trazado que la zanja 2. Desaparecen la ue 1 y ue 2. En esta parte además, bajo una muy somera capa de tierra marrón, aparece la roca madre, a unos $50 \mathrm{~cm}$ de profundidad. Ésta es una de las dos referencias de profundidad que se tienen de la roca madre (la otra está en la cata $4 \times 4$ ), esquisto en ambos casos.

La zanja 2 termina con la excavación de un tramo de zanja transversal que la une, a través de la carretera, con otra zanja que había sido excavada previamente, antes de iniciarse la intervención arqueológica. No aparece material. El relleno es también piedra desmenuzada y arena.

ZANJA 4: en su parte inicial tiene unos $20 \mathrm{~cm}$ de profundidad, y después va ganándola. En la primera parte aparece cerámica muy escasamente, y luego prácticamente desaparece. Es todo un nivel de relleno. El último tramo de esta zanja se une con la zanja 1.

ZANJA 3: parte del extremo $\mathrm{O}$ de la zanja 2, a través de la carretera y continúa al otro lado. Aparece la misma estratigrafía de la zanja 2, y la continuidad con ésta es total. Sin embargo hay un cambio de color en la tierra muy acusado: aunque también es relleno, se trata de una tierra amarillenta y mezclada con escombro. Hasta este punto, esta zanja 3 es muy rica en cerámica.

En relación con ella merece la pena comentar que cuando se realizó el perímetro de cimentación del baño, a $60-70 \mathrm{~cm}$ de profundidad, parece que afloró también cerámica prehistórica en fragmentos grandes, por el lado O. Este zanjeo fue previo al programa de intervención arqueológica.

ZONA DE JUEGOS INFANTILES: requirió la excavación de aproximadamente $30 \mathrm{~cm}$ de profundidad en un área de unos $15 \times 8 \mathrm{~m}$. Se documenta de nuevo la misma estratigrafía que en la zanja 2 y en la 3 . La apertura en "extensión" en esta parte permitió saber que la profundidad de la ue 2 es irregular, y la cerámica muy abundante. Confirmando la posibilidad de estructuras de la zanja 2, se documentó un afloramiento de piedras de forma aproximadamente circular, que no se excavó. Asimismo aparece bajo la ue 2 un nivel arcilloso comparable a la ue 3 de la zanja 2, que también se denomina ue 3.
La zona de juegos infantiles se completa con una zanja de drenaje en la esquina NE, a la misma profundidad. Esta parte es exclusivamente arena blanca, completamente suelta, con algunas piedras. Se debe a un relleno anterior, de fecha desconocida, precisamente también para una zona de juegos infantiles. No aparece material arqueológico.

CATA 4X4: se abrió ampliando un tramo de la zanja 1, en el lugar donde los técnicos de la Dirección General de Patrimonio Cultural detectaron un cambio en la coloración del sedimento. La tierra blanca que entonces se observaba se tomó como un posible indicio de estructuras.

Lo más relevante de la estratigrafía de la cata $4 \times 4$ es lo que sigue. Se documentan de nuevo la ue 1, relleno, suelto, con terrones y piedras, $\mathrm{y}$, a profundidad variable, la ue 2, arqueológico, más compacto, marrón claro, más duro. Contiene huesos y cerámica, suelta, rodada, en fragmentos no muy grandes. En concreto en la esquina NO aparece mucha cerámica.

En la zona $\mathrm{O}$ bajo la ue 2 aparece una ue 3 apenas discriminable. Es una tierra muy suelta, más vegetal, marrón oscura, muy somera. Destaca especialmente la aparición de hueso.

Bajo la ue 2 (ue 3 en la zona O) se documenta la ue 4. En general la transición entre ambas es difícil de determinar. La ue 4 es una tierra más blanda, suelta, de color marrón oscuro, con terrones algo gruesos. La capa superficial de esta ue aparecía más endurecida, pero al levantarla aparece ese sedimento más suelto. En la zona N, especialmente, aparecen abundantes piedras. Destaca también la aparición de huesos largos y mandíbulas animales. Asimismo, también es abundante el material de construcción. De hecho en la esquina NO aparece una concentración bastante significativa de este material, quemado y sin quemar. Se denominó ue 5. Muy cerca, a unos $50 \mathrm{~cm}$ de profundidad, es destacable una acumulación de cerámica, junto con una lingotera bastante entera (lámina 1).

En la zona S de la cata, incluido en la ue 4, apareció un afloramiento de piedras que se denominó ue 7 , que corre prácticamente en sentido O-E. Otras acumulaciones de piedras se relacionan también con él: en la parte E, próxima al perfil, algunas piedras de tamaño regular-grande caidas hacia la zona $\mathrm{S}$; en la parte $\mathrm{E}$, al $\mathrm{N}$ de la ue 7 , una concentración a profundidades entre 78 y $84 \mathrm{~cm}$, y que llegan hasta entre 89 y $100 \mathrm{~cm}$; en la parte $\mathrm{O}$, al $\mathrm{N}$ de la ue 7 también, otra concentración de piedras algo más pequeñas. La ue 7 propiamente dicha se compone en general de una serie de grandes piedras, bajo las cuales aparecen huesos y otro material, y una agrupación de otras piedras de menor tamaño. Sólo se 


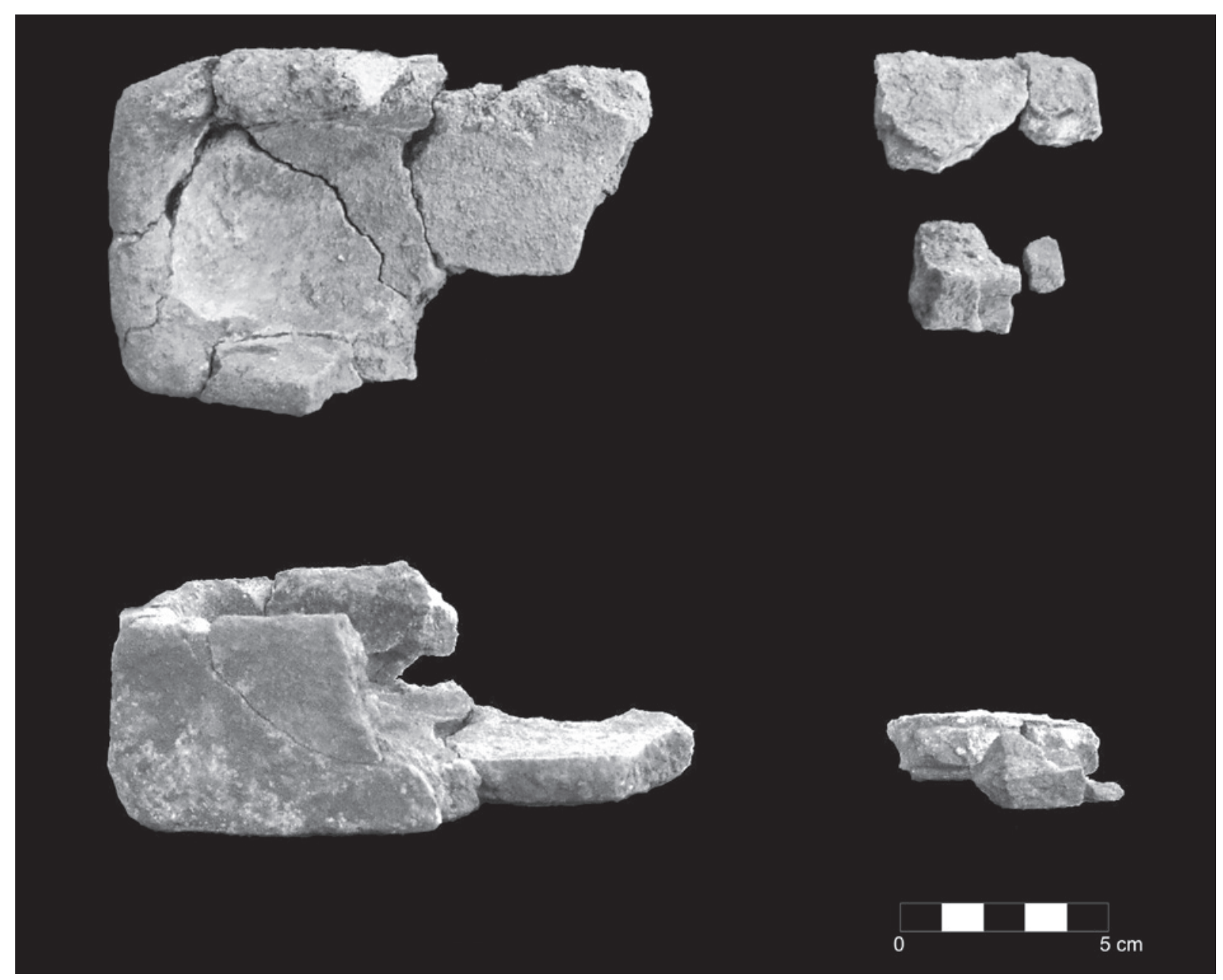

Lámina 1. Fragmento de lingotera.

conserva una primera hilada de piedras, no hay diferencia sedimentaria entre las zonas $\mathrm{N}$ y S, y las variaciones en la cantidad de material recogido en ambas deben atribuirse a la diferencia de sus dimensiones, aunque es llamativa la abundancia relativa de cazuelas y decoración en el sector $\mathrm{S}$. Todas estas evidencias impiden considerar que la ue 7 haya creado áreas funcionales o de otra clase. Por otro lado, no es susceptible de ser natural, al presentar tal acumulación y estructura. Aparece material arqueológico sobre las piedras, debajo y entre ellas (cerámica, cuarcita, material de construcción). La cerámica que aparece en la ue 4 bajo la ue 7 está más fragmentada que la del resto de la ue 4.

Bajo la ue 4 se documenta la ue 6, un estrato heterogéneo en el que ya se perciben claras diferencias horizontales, debidas quizá a los niveles que tiene debajo: la estratigrafía inferior a la ue 6 empieza a variar de E a O. La ue 6 contiene los mismos materiales que las uuee anteriores (hueso, cerámica, material de construcción). Es destacable, en la zona SE, una mancha de tierra roja, acumulada y apelmazada, y ceniza, de cierta profundidad, que luego se definirá como ue 12. Estéril en material arqueológico, contenía unas 21 piedras, unas encima de otras, la mayoría con caras planas, pero no trabajadas.

Debajo de la ue 6 se documenta la ue 9, un estrato de tierra de color marrón, grumosa, oscura, con material arqueológico de las mismas características que en los anteriores niveles. Debajo se alcanza la roca madre.

La ue 9 no se documenta en la franja $\mathrm{O}$, donde la estratigrafía es bastante más compleja: a una ue 8 , de ceniza, con material concrecionado de ceniza, pero no quemado, aparentemente, sigue una ue 10, de tierra blanca, casi yeso. Es algo heterogénea: hacia el $\mathrm{N}$ 
la tierra va haciéndose más amarillenta, pero se considera la misma ue. Las dimensiones de las ue 8 y 10 son parecidas: un metro de ancho, y una longitud variable, unos tres metros y medio y unos dos metros, respectivamente. Bajo la ue 10 se definieron la ue $15 \mathrm{y}$, en su interior, las ue 13 y ue 14 , contiguas.

La ue 15 es un rebaje intencional de la roca madre. Dentro de ella había una alta concentración de diversas capas de ceniza y tierra blanca extremadamente fina. El material arqueológico recuperado es abundante. La mitad S del relleno de la ue 15 se denomina ue 13 , y la mitad N, ue 14. Ambas forman una unidad, pero se distinguen por ligeras variaciones en el color del sedimento. Junto con la ue 15 , forman claramente una sola actividad. Debido a la complejidad estratigráfica de esta parte aún se definieron dos uuee más (16 y 18), que solamente discriminan determinadas áreas incluidas en la ue 13.

ZANJA TRANSVERSAL, ZONA JUEGOS INFANTILES: es una pequeña zanja que cruza la zona de juegos infantiles. Empieza a 9'40 m de la esquina SO, con una anchura de unos $20 \mathrm{~cm}$, variable. El largo corresponde a la anchura de la zona de juegos infantiles, unos $8 \mathrm{~m}$. Su profundidad es de aproximadamente $15 \mathrm{~cm}$, también variable.

Tiene el interés de ser una intrusión en el nivel arqueológico, ue 2. Abunda en ella la cerámica y el material de construcción, más en el lado $\mathrm{S}$, donde aparece en conexión con grandes piedras, que emergen aquí con cierta profusión. Es posible relacionar estas piedras con el afloramiento circular antes comentado, porque todas están aproximadamente en la misma cota, en la misma ue. Se confirma así la posibilidad de que a esta profundidad (unos $45 \mathrm{~cm}$ ) existan ya estructuras de cierta entidad. Pero ninguna de estas posibles estructuras se excavó.

ZANJA 5: sólo se documenta un nivel revuelto de tierra marrón claro, suelta, en terrones de considerable tamaño. Tiene muchas piedras grandes, pero muy escaso material arqueológico.

Las intervenciones más productivas fueron la de la zanja 2, la zona de juegos infantiles y la cata $4 \times 4$. En conjunto han permitido documentar con una cierta 'extensión' diferentes puntos del yacimiento, y confirmar que los materiales y la primera parte de la estratigrafía son, grosso modo, los mismos. Todo el nivel superficial de la meseta del cerro es un relleno que parece llegar hasta el borde N. Esta topografía deformada por las alteraciones contemporáneas impide apreciar la existencia de posibles líneas de muralla $u$ otras estructuras.
Aparte del área intervenida (unos 100 m x 90 m), no es posible hacer una estimación de la extensión del poblado debido a la falta de cualquier evidencia en superficie.

\section{MATERIALES}

\section{Cerámica}

Se recuperaron 3480 fragmentos, más 863 que fueron inventariados. De estos se clasificaron 693 (80’2\%) (tabla 1).

Tabla 1. Distribución de la tipología cerámica.

\begin{tabular}{|l|r|c|}
\hline \multicolumn{1}{|c|}{ Tipo } & Total & \multicolumn{1}{c|}{$\%$} \\
\hline Cuencos carenados & 2 & $0^{\prime} 2$ \\
\hline Plato carenado & 2 & $0^{\prime} 2$ \\
\hline Tapadera & 3 & $0^{\prime} 4$ \\
\hline Vaso & 11 & $1^{\prime} 6$ \\
\hline Cazuelas & 19 & $2^{\prime} 7$ \\
\hline Recipiente de paredes gruesas & 22 & $3^{\prime} 1$ \\
\hline Ollas cerradas & 127 & $18^{\prime} 3$ \\
\hline Platos & 129 & $18^{\prime} 6$ \\
\hline Ollas & 139 & 20,0 \\
\hline Cuencos & 238 & $34^{\prime} 34$ \\
\hline
\end{tabular}

La clasificación tipológica se ha realizado con criterios algo abiertos, que básicamente permiten decidir sobre la regularidad de este yacimiento en relación con el contexto calcolítico de la zona. Para definir los recipientes se aplicaron los siguientes argumentos:

- cazuela: recipiente de paredes más bajas que el cuenco, y más abierto que éste. Tiene carena.

- cuenco: recipiente con tendencia esférica (aunque hay algún caso con carena). La boca puede tender también a cerrarse un poco.

- vaso: recipiente de paredes altas. Pueden ser rectas o tendentes a rectas.

- olla: recipiente de paredes normalmente más gruesas que los cuencos, destinados a otra funcionalidad. Tienen formas también más variadas (globulares, perfil en S....) pero en la base de datos solamente se ha diferenciado olla y olla cerrada. Esta puede solaparse de alguna manera con el cuenco, porque su distinción se basa en un grado subjetivo de cierre de la boca. En general se asume que la olla es más cerrada. 
- plato: recipiente de paredes extremadamente bajas. Puede tener borde y pared exvasados, muy hacia fuera. Puede también estar carenado y tener pared recta.

- recipientes de paredes gruesas: se utiliza esta categoría para los recipientes que no se definen como ollas por ser excesivamente grandes. Podrían ser recipientes de contención.

Los tratamientos más habituales son el alisado y el bruñido (tabla 2), y podría haber también un caso de tratamiento a la almagra.

Tabla 2. Tratamientos.

\begin{tabular}{|l|c|c|c|}
\cline { 2 - 4 } \multicolumn{1}{c|}{} & Exterior & Interior & Juntos \\
\hline Engobe & 1 & 1 & 0 \\
\hline Espatulado & 4 & 4 & 0 \\
\hline Escobillado & 54 & 85 & 14 \\
\hline Bruñido & 171 & 103 & 51 \\
\hline Alisado & 463 & 529 & 331 \\
\hline
\end{tabular}

En cuanto a la distribución de la cerámica por áreas, en la zanja 2 se detectó una cierta concentración, teniendo en cuenta tanto selecta como no selecta, en los tramos 10, 11, 12 (figura 4). Esta zona está aproximadamente alineada con la cata $4 \times 4$, y además en las cercanías de la zona de juegos infantiles. Las tres áreas presentan una alta densidad de materiales arqueológicos, y quizá se las pueda considerar, con la evidencia de que se dispone, los límites N-S del yacimiento. En conjunto delimitan una zona de unos $90 \mathrm{~m}$ de largo.

En la cata $4 \times 4$ es posible observar una variación importante en la distribución de la cerámica a través de las distintas uuee (tabla 3). En principio parece que se da aproximadamente la misma proporción entre cerámica selecta y no selecta en todas las uuee, lo cual resulta lógico si no hay ningún sesgo que permita una mejor conservación de las formas o de los galbos en cada una de ellas. Es significativo que a partir de la ue 4 se documentó mucha más abundancia de material. Asimismo, las decoraciones cerámicas empiezan a aparecer en esta ue.

Las uuee 4, 6 y 9 mantienen aparentemente las mismas proporciones de tipologías, es decir, cuencos, platos y ollas, por este orden, aunque la cantidad total de material en la 9 sea menor (debido probablemente a su menor extensión). Esto hace que no se pueda detectar un cambio sustancial en la funcionalidad que esos estratos, como diferentes niveles de ocupación, reflejan.

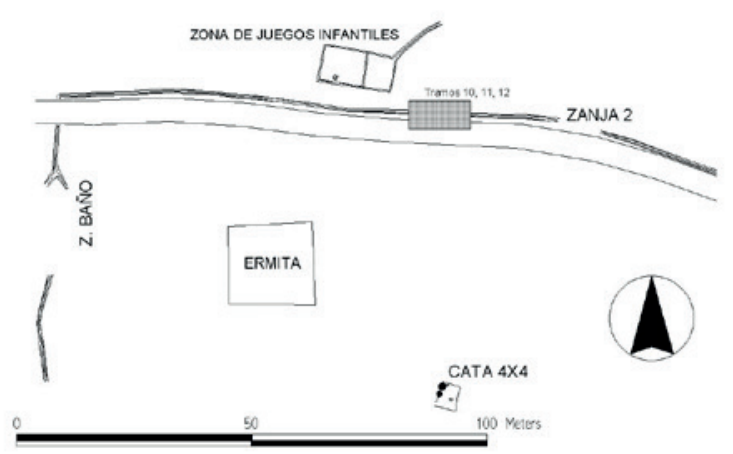

Figura 4. Plano con intervenciones y zona de mayor concentración de material de la zanja 2.

Por otro lado, claramente la actividad 1 (uuee 13, $14,15,16$ y 18) es un nivel de ocupación constatado, y la estructura más interesante de la excavación (lámina 2). Es el fondo de una vivienda, aunque solo se ha podido documentar su mitad E, ya que la otra quedó tapada. Tiene, significativamente, algunas piezas relevantes, únicas entre el material recuperado y en algún caso poco frecuentes en general en lo que se conoce del calcolítico: un posible soporte de cuenco de tipo carrete (Martín 1986, figuras 5 y 35; Martín 1994, figura 85) (SIE/2005/7/14/1), una bandeja poco profunda con lengüeta para transportar (SIE/2005/7/13/16), y un pequeño cuenco prácticamente entero (SIE/2005/7/13/23).

En cuanto a otras piezas dignas de comentario, fuera de la actividad 1, destaca la SIE/2005/7/6/208, una olla cerrada, probablemente la más completa recuperada, en 27 fragmentos. Tiene unas concreciones especiales de tierra anaranjada. Apareció en la zona central de la ue 6. También destaca una pieza con dos bordes a distintos niveles (SIE/2005/7/8/15). Parece ser un recrecimiento del borde original del cuenco.

Las decoraciones encontradas son dos fragmentos del tipo conocido como pastillas repujadas (SIE/2005/2/1/20 y SIE/2005/2/1/27), un fragmento con una combinación de puntos impresos y líneas paralelas incisas (SIE/2005/2/1/55), un fragmento con líneas impresas (SIE/2005/7/4/145), un fragmento con chèvrons rellenos de puntos impresos, en el que aún podría apreciarse un lado de un triángulo (ya que son habituales los triángulos enfrentados) (SIE/2005/1/1/16), $\mathrm{y}$ un fragmento con ungulaciones, que podrían estar dentro de al menos una línea incisa (SIE/2005/7/9/20). Hay dos fragmentos que podrían llegar a considerarse decorados con pintura (SIE/2005/7/18/4 y SIE/2005/7/14/1). 
Tabla 3. Distribución de la cerámica por ues en la cata $4 \times 4$.

\begin{tabular}{|c|c|c|c|c|c|c|c|c|c|c|}
\hline UE & Cazuela & Cuenco & Olla & $\begin{array}{l}\text { Olla } \\
\text { cerrada }\end{array}$ & Plato & $\begin{array}{l}\text { Recipiente de } \\
\text { paredes gruesas }\end{array}$ & Tapa & Vaso & Total & $\begin{array}{c}\text { Total cerámica } \\
\text { no selecta }\end{array}$ \\
\hline 1 & & 2 & 4 & 2 & 1 & & & & 9 & 34 \\
\hline 2 & & 6 & 3 & 6 & 3 & & & 1 & 19 & 125 \\
\hline $2-3$ & & 1 & 1 & & 1 & & & & 3 & 21 \\
\hline 4 & 6 & 59 & 36 & 19 & 22 & 6 & 2 & 1 & 151 & 731 \\
\hline $4-5$ & 1 & & 3 & & 1 & & & & 5 & 9 \\
\hline 5 & & & 1 & & & & & & 1 & 7 \\
\hline 6 & 5 & 60 & 23 & 38 & 35 & 3 & 1 & 2 & 167 & 840 \\
\hline 7 & & 2 & 1 & 1 & 1 & & & & 5 & 69 \\
\hline 8 & & 11 & 3 & 1 & 3 & & & & 18 & 81 \\
\hline 9 & 4 & 26 & 17 & 11 & 14 & 3 & & 2 & 77 & 327 \\
\hline 10 & 1 & 14 & 7 & 10 & 13 & 2 & & & 47 & 271 \\
\hline 13 & & 9 & 3 & 9 & 9 & & & 2 & 32 & 175 \\
\hline 14 & & 7 & 1 & 1 & & & & 1 & 10 & 27 \\
\hline 18 & & 1 & 5 & 3 & & & & & 9 & 38 \\
\hline
\end{tabular}

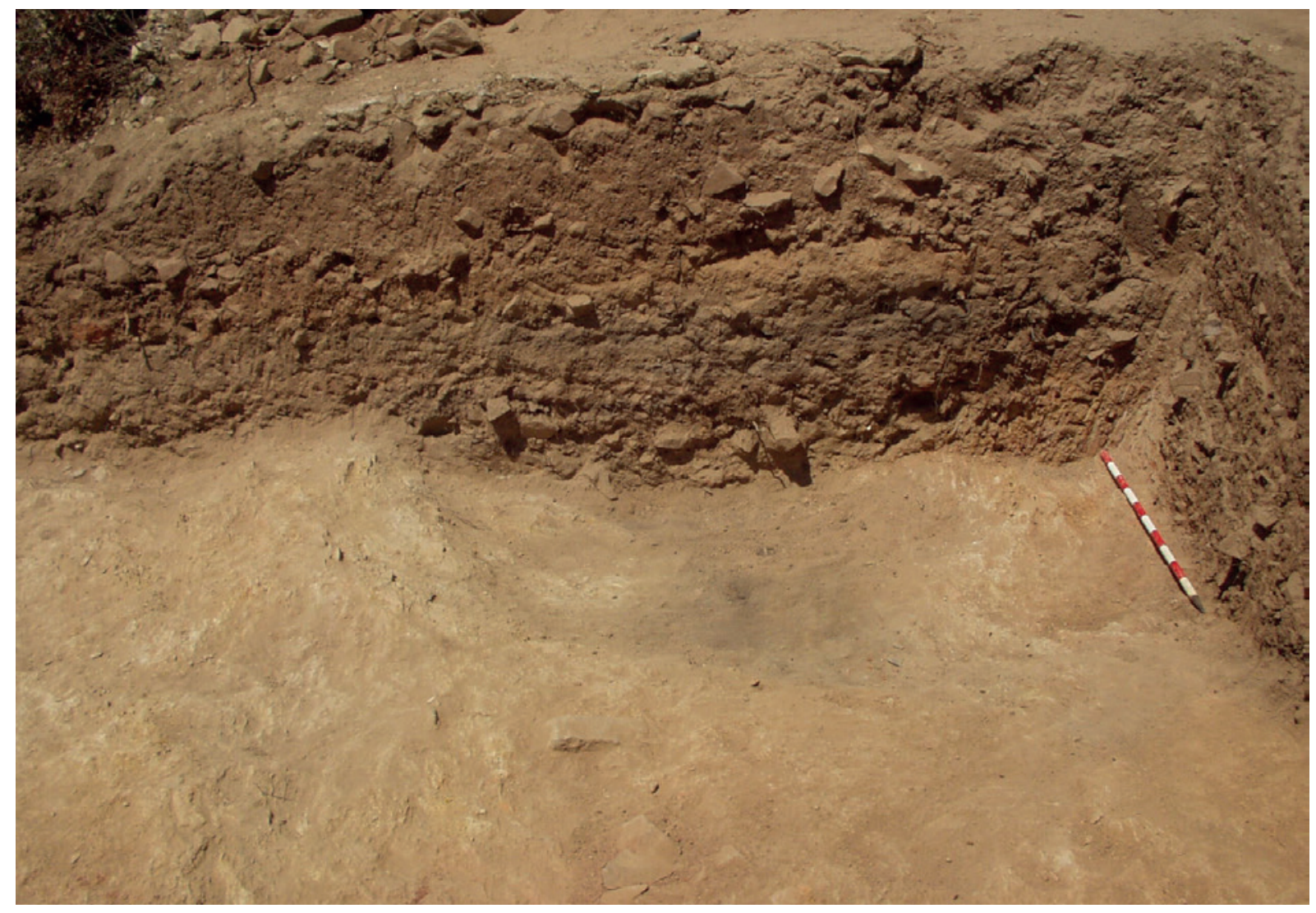

Lámina 2. Vista de la actividad 1, cortada aproximadamente por la mitad por el perfil oeste. 
Las cazuelas carenadas han sido utilizadas generalmente como indicador cronotipológico del Neolítico final en todo el Suroeste peninsular, aunque su aparición en porcentajes bajos es común en bastantes poblados del III milenio cal BC. Este es el caso también en La Sierrecilla (tabla 4). Dentro de la cata $4 \times 4$ los recipientes carenados se encuentran mayoritariamente a partir de la ue 4 , pero no parecen concentrarse en los estratos inferiores. Es interesante que al menos dos elementos se dan en los niveles asociados con la casa (uuee 10 y 13), pero los demás no proceden de esta parte de la cata. Esta evidencia no es suficiente para proponer que la casa pertenezca a una fase más antigua de ocupación. En cualquier caso las carenas vuelven a marcar una clara diferencia entre la ue 4 e inferiores y las capas superficiales.

Tanto en el caso de las pastillas repujadas como en los demás no hay en principio ningún elemento que permita inferir un origen externo para estas cerámicas. El paralelo más claro para las pastillas repujadas es La Pijotilla (Hurtado 1984), aunque se dan en yacimientos de toda la península desde Francia (que se considera el origen de este motivo decorativo) a Badajoz, siempre como producciones locales (Hurtado y Amores 1982; Estrada et alii 1999). Sin embargo también se ha propuesto la posibilidad de que sea una técnica característica del Neolítico final, al menos en Andalucía occidental (Enríquez 1990: 187).

Estas decoraciones se encuentran bien representadas en los materiales de la Cabaña de Cabrerizas (González et alii 1991), un yacimiento situado en la cuenca extremeña del Tajo, que cuenta con una datación absoluta para esta ocupación de 4060土85 BP, y también en el poblado de Canchal (Bueno et alii 2000), donde además de pastillas repujadas se recogieron en superficie algunos fragmentos de cerámicas con pintura negra.

En conjunto, la información que ha proporcionado la cerámica parece remitir, por comparación tipológica con otros yacimientos, a una ocupación de La Sierrecilla durante gran parte del III milenio cal $\mathrm{BC}$, sin que pueda establecerse nítidamente un inicio del asentamiento durante períodos previos. La ausencia de cerámicas campaniformes, bien conocidas en otros yacimientos de la zona (Enríquez 2003) podría interpretarse, con cierta probabilidad, en términos de abandono del sitio durante la mitad del III milenio cal BC, dentro de una dinámica de poblamiento que puede extrapolarse a otros poblados de la cuenca del Guadiana.
Tabla 4. Carenas. Cata $4 \times 4$.

\begin{tabular}{|c|c|c|c|}
\hline Area & $\mathrm{Ue}$ & Morfología & Forma cerámica \\
\hline Cata $4 \times 4$ & 1 & Carena & \\
\hline Cata $4 \times 4$ & 2 & Carena & \\
\hline Cata $4 \times 4$ & 4 & Carena & Cazuela \\
\hline Cata $4 \times 4$ & 4 & Galbo (carena) & $\begin{array}{l}\text { Recipiente de } \\
\text { paredes gruesas }\end{array}$ \\
\hline Cata $4 \times 4$ & 4 & Borde, carena & Cazuela \\
\hline Cata $4 \times 4$ & 4 & Carena & \\
\hline Cata $4 \times 4$ & 4 & Carena & Cazuela \\
\hline Cata $4 \times 4$ & $4-5$ & Borde, carena & Cazuela \\
\hline Cata $4 \times 4$ & 6 & Borde, carena & Cazuela \\
\hline Cata $4 \times 4$ & 6 & Carena & Olla \\
\hline Cata $4 \times 4$ & 6 & Borde, carena & Cazuela \\
\hline Cata $4 \times 4$ & 6 & Carena & \\
\hline Cata $4 \times 4$ & 6 & Carena & Cazuela \\
\hline Cata $4 x 4$ & 9 & $\begin{array}{l}\text { Borde plano, } \\
\text { carena }\end{array}$ & Plato carenado \\
\hline Cata $4 \times 4$ & 9 & Borde, carena & Cazuela \\
\hline Cata $4 \times 4$ & 9 & Carena & Cazuela \\
\hline Cata $4 \times 4$ & 10 & Borde, carena & Cazuela \\
\hline Cata $4 \times 4$ & 13 & Borde, carena & Plato carenado \\
\hline Zanja 2 & 1 & Borde, carena & $\begin{array}{l}\text { Recipiente de } \\
\text { paredes gruesas }\end{array}$ \\
\hline Zanja 2 & 1 & Borde, carena & $\begin{array}{c}\text { Cuenco care- } \\
\text { nado }\end{array}$ \\
\hline Zanja 2 & 1 & Carena & \\
\hline Zanja 3 & 1 & Borde, carena & $\begin{array}{c}\text { Cuenco care- } \\
\text { nado }\end{array}$ \\
\hline Zanja 3 & 1 & Borde, carena & Olla \\
\hline Zanja 3 & 1 & Carena & \\
\hline Zanja 5 & 1 & Carena & Cazuela \\
\hline $\begin{array}{c}\text { Zanja transversal, } \\
\text { zona juegos } \\
\text { infantiles }\end{array}$ & 1 & $\begin{array}{c}\text { Borde plano, } \\
\text { carena }\end{array}$ & Plato \\
\hline $\begin{array}{c}\text { Zanja transversal, } \\
\text { zona juegos } \\
\text { infantiles }\end{array}$ & 1 & Borde, carena & Cazuela \\
\hline $\begin{array}{l}\text { Zona de juegos } \\
\text { infantiles }\end{array}$ & 1 & Carena & \\
\hline $\begin{array}{l}\text { Zona de juegos } \\
\text { infantiles }\end{array}$ & 1 & Carena & $\begin{array}{l}\text { Recipiente de } \\
\text { paredes gruesas }\end{array}$ \\
\hline
\end{tabular}




\section{Otros}

En barro cocido, además de dos bolas de funcionalidad desconocida, se han inventariado 7 fragmentos de los elementos denominados crecientes. El fragmento SIE/2005/6/1/41 se diferencia mucho de los otros, tanto por su tamaño como por su elaboración. Los otros son simples fragmentos de cilindros estrechos, mientras que en este caso se trata de una media luna de cierta anchura, con una perforación y una hendidura en cada extremo. Está quemado. Esto es relativamente habitual porque pueden estar relacionados con hornos.

Se consideran típicos del calcolítico pleno.

La industria sobre hueso es prácticamente inexistente. Sólo se ha recuperado un fragmento trabajado, cortado en sus dos extremos y pulido. Podría ser un enmangue, quizá sin terminar, pero esta determinación no es segura.

\section{Lítica}

Destaca la presencia de numerosos cantos de río en cuarcita (30 piezas), en su mayoría sin trabajar y sin trazas aparentes. De éstos alguno presenta marcas de "picoteo" consecuencia de su uso como machacador, o con caras alisadas, resultado de una fricción prolongada al ser utilizados como alisadores o pulidores. También podrían ser manos de molino, en el caso de las de mayor tamaño y forma más esférica. Hay en todo caso una mano de molino característica, trabajada sobre granito o granodiorita (SIE/2005/L/7/4/1). Sus peculiaridades granulométricas la convierten en una herramienta de mayor utilidad para esta función. Otra de estas "molederas" (SIE/2005/7/4/2) resulta especialmente llamativa por la presencia en una de sus caras de un rebaje de tipo circular rotatorio al cual no se puede asignar una función.

El resto de materiales son pizarras, sin uso aparente o imposible de identificar, dada su facilidad para exfoliarse o fracturarse; esquistos, muy abundantes, ya que son el constituyente prioritario de la zona; y cuarzos lechosos o negros. Entre estos materiales los que aparecen trabajados son prácticamente nulos, con la excepción de una plaqueta de esquisto con un orificio troncocónico central, sin funcionalidad asignada (SIE/2005/L/7/2/1).

La cuarcita es el material más ampliamente utilizado. Esto es fácil de explicar teniendo en cuenta la proximidad de un pequeño cauce fluvial (río Búrdalo) al yacimiento. Así, los cantos de río se utilizaron en función de su forma para diversos usos, y fueron un material fácilmente desechable por su gran abundancia. A la vez la cuarcita fue una fuente importante de materia prima para la realización de útiles, entre los que se han encontrado lascas, perforadores e incluso hachas. Sin embargo de estas últimas solo se cuenta con fragmentos de los posibles cuerpos, sin la parte distal. Es interesante destacar la presencia de dos cantos de río trabajados (SIE/2005/L/2/1/2 y $\mathrm{SIE} / 2005 / \mathrm{L} / 1 / 1 / 1)$. La aparición de estas piezas, denominadas "macrolíticas", en el Suroeste peninsular (Raposo y Silva 1984) ha generado diversas interpretaciones: desde su atribución a cronologías epipaleolíticas y neolíticas, a su tratamiento como elemento diagnóstico de fases cronoculturales como el Languedocense. Su aparición, cada vez más frecuente, en contextos variados, incluyendo sobre todo yacimientos calcolíticos del centro-oeste peninsular, tanto poblados (Cerrillo 2005; Enríquez 1988; López-Romero 2005) como dólmenes (López-Romero 2005), plantea la necesidad de analizar estos productos líticos como un tipo de herramienta más, quizá asociada a la ausencia de sílex y otros materiales.

De hecho el sílex tiene una escasa representación en La Sierrecilla: solo una lasca (SIE/2005/L/7/13/3), que bien pudiera ser un producto de debitado. Es preciso tener en cuenta la escasa superficie excavada, pero resulta llamativa esta carencia tratándose de un material de uso tan extendido. Sin embargo no es extraña también en otras zonas de la cuenca del Guadiana, donde las áreas de aprovisionamiento están alejadas.

Dentro de la cata 4x4 (área 7) aparecieron dos molinos sobre arenisca de pequeñas dimensiones. Uno con forma circular y base plana (SIE/2005/L/7/13/2) y otro de cara elíptica y base triangular (SIE/2005/L/7/9/1) para su inserción o apoyo tanto en un caballete como hincado en el suelo. Ambos tienen la pátina brillante característica de la superficie de fricción, y fracturas en alguno de sus extremos.

La pieza más excepcional es un fragmento distal de hacha pulimentada (SIE/2005/L/7/13/1) de un solo bisel manufacturada sobre diorita negra.

Por último, es de destacar también la aparición de dos fragmentos de roca de poca densidad, dada la gran cantidad de vacuolas que presentan, características de las rocas volcánicas o escorias. Son pumitas, producidas en las explosiones volcánicas. No parecen haber sido trabajadas, y están concrecionadas en algunas zonas, como si hubieran estado expuestas. No es posible deducir una utilidad aparente, pero resulta llamativa su presencia porque no son características de la composición litológica de la zona. Es, por tanto, un elemento exógeno aportado, quizá de la zona volcánica conocida como Campo de Calatrava, o su área de influencia. 
Como característica de conservación, que se ha observado tanto en el material lítico como en los restos óseos de fauna, se distingue la presencia de costras de calcificación en una de las caras de los cantos recuperados en la cata $4 \times 4$. Esto viene a indicar que estos materiales estuvieron en algún momento semienterrados mientras una de las caras quedaba expuesta durante largo tiempo a fluctuaciones o corrientes hidráulicas. Así se explicaría la baja presencia de materiales de pequeño tamaño y poco peso como puede ser la industria sobre sílex.

Así pues, como conclusión, se puede señalar que la industria lítica recuperada en La Sierrecilla tiene una baja representatividad, y su funcionalidad predominante parece orientarse al procesado de cereales y a la manufactura de cerámica.

\section{Fauna}

Se han recuperado un total de 416 fragmentos óseos, de los que tan sólo se han podido identificar 159, correspondientes a 8 taxones de mamíferos. No se ha documentado la presencia de restos humanos ni de aves $\mathrm{u}$ otros vertebrados (tabla 5).

Tabla 5. Restos óseos por taxones y partes del esqueleto.

\begin{tabular}{|c|c|c|c|c|c|c|c|c|c|}
\hline & Bos & Equus & $\begin{array}{l}\text { Cervus } \\
\text { elaphus }\end{array}$ & Sus & $\mathrm{O} / \mathrm{C}$ & $\begin{array}{l}\text { Ovis } \\
\text { aries }\end{array}$ & $\begin{array}{c}\text { Canis } \\
\text { familiaris }\end{array}$ & $\begin{array}{l}\text { Capreolus } \\
\text { capreolus }\end{array}$ & TOTAL \\
\hline Asta & & & 13 & & & & & 1 & 14 \\
\hline Núcleo óseo & & & & & & & & & 0 \\
\hline Cráneo & 1 & & & 5 & & & & & 6 \\
\hline Maxilar & & & & 1 & & & & & 1 \\
\hline Mandíbula & 1 & 1 & & 1 & & & & & 3 \\
\hline Dientes aislados & 2 & 7 & 1 & & 3 & & & & 13 \\
\hline Vértebra & 2 & 2 & & 1 & & & & & 5 \\
\hline Sacro & & & & & & & & & 0 \\
\hline Costilla & & 1 & & & 2 & & & & 3 \\
\hline Escápula & 3 & & 2 & 6 & 2 & & & & 13 \\
\hline Húmero & 1 & 1 & & 5 & & 1 & & & 8 \\
\hline Radio & 2 & & 2 & 2 & & & & & 6 \\
\hline Ulna & 1 & 1 & & 4 & & & & & 6 \\
\hline Carpo & 3 & 1 & & & & & & & 4 \\
\hline Metacarpiano & 1 & & & 5 & & & & & 6 \\
\hline Pelvis & 1 & 3 & 1 & 3 & & & & & 8 \\
\hline Fémur & 1 & 2 & & & & & & & 3 \\
\hline Tibia & & & 4 & 2 & 1 & & 1 & & 8 \\
\hline Rótula & 2 & & & & & & & & 2 \\
\hline Calcáneo & & 1 & 2 & 2 & & & & & 5 \\
\hline Astrágalo & 1 & 1 & 2 & 1 & & & & & 5 \\
\hline Tarso & & 2 & 1 & & & & & & 3 \\
\hline Metatarsiano & 2 & 1 & 1 & 2 & 2 & & & & 8 \\
\hline Metap. indet.. & 2 & 1 & 1 & & & & & & 4 \\
\hline Falange & 12 & 3 & 7 & 2 & 1 & & & & 25 \\
\hline TOTAL & 38 & 28 & 37 & 42 & 11 & 1 & 1 & 1 & 159 \\
\hline
\end{tabular}


Los huesos de animales claramente domésticos son de ovicápridos, oveja (Ovis aries) y , por otro lado, perro (Canis familiaris). Las especies salvajes representadas son ciervo (Cervus elaphus) y corzo (Capreolus capreolus). Pero la discriminación salvaje/doméstico en los suidos, los bóvidos y los équidos es difícil. En el caso de los suidos, la falta de suficientes restos de cráneo u otros fragmentos relevantes ha impedido decidir si se trata de jabalí (Sus scrofa) o cerdo (Sus domesticus). Y en lo que se refiere a bóvido y équido, el gran tamaño de los restos (tabla 6) permite sostener tanto que se trata de fauna salvaje como en proceso de domesticación (quizá en el caso de los bóvidos parece más probable la presencia de uro que de vaca). También es muy posible que tanto en bóvidos como équidos estén presentes ambos: Bos primigenius y Bos taurus, y Equus ferus y Equus caballus. Este patrón se ha documentado en asentamientos como Los Castillejos (Fuente de Cantos, Badajoz) (Castaños 1998). Así, en el debate sobre si esta zona fue un foco de domesticación del uro y del caballo durante este periodo (Castaños 1991), es poco lo que la fauna de La Sierrecilla puede aportar, aunque las medidas obtenidas de los fragmentos óseos pueden ser cotejadas con otras muestras (tabla 6).

El perro es muy escaso, y es muy posible que no fuera consumido (Castaños 1998). El fragmento recuperado no tiene marcas. Sin embargo en el conjunto de

Tabla 6: Medidas aisladas en mm del esqueleto postcraneal. LM: Longitud Máxima. AMP: Anchura Máxima Proximal. AmDiáfisis: Anchura Mínima de la Diáfisis. AMD: Anchura Máxima Distal.

\begin{tabular}{|c|c|c|c|c|}
\hline Bóvido & LM & AMP & AmDiáfisis & AMD \\
\hline Radio & - & 111 & - & - \\
\hline $\mathrm{I}^{\mathrm{a}}$ Falange & 74 & 42 & 35 & 39 \\
\hline $\mathrm{I}^{\mathrm{a}}$ Falange & 70 & 37 & 31,5 & 33,5 \\
\hline $\mathrm{I}^{\mathrm{a}}$ Falange & 74 & 36,5 & 32,5 & 34 \\
\hline II $^{\text {a }}$ Falange & 52 & 38 & 29,5 & 32,5 \\
\hline Astrágalo & - & 70 & 63,5 & 44 \\
\hline II $^{\mathrm{a}}$ Falange & 47 & 34 & 27 & 29 \\
\hline $\mathrm{I}^{\mathrm{a}}$ Falange & 78 & 44 & 40 & 42 \\
\hline Humero distal & - & - & - & 89 \\
\hline $\mathrm{I}^{\mathrm{a}}$ Falange & 77 & - & 29 & 35,5 \\
\hline Équido & LM & AMP & AmDiáfisis & AMD \\
\hline Fémur & 398 & 107,5 & 39 & 86,5 \\
\hline III ${ }^{\mathrm{a}}$ Falange & - & 61 & - & - \\
\hline Astrágalo & - & - & - & - \\
\hline MT III & - & 44 & - & - \\
\hline Ciervo & LM & AMP & AmDiáfisis & AMD \\
\hline $\mathrm{I}^{\mathrm{a}}$ Falange & 54 & 21 & 16 & 20 \\
\hline $\mathrm{I}^{\mathrm{a}}$ Falange & 51 & 20 & 15 & 19,5 \\
\hline Radio & - & 53,5 & - & - \\
\hline $\mathrm{I}^{\mathrm{a}}$ Falange & 50,5 & 18 & 14 & 16,5 \\
\hline $\mathrm{I}^{\mathrm{a}}$ Falange & 51,5 & 20 & 15,5 & 18 \\
\hline Tibia & - & - & - & 44 \\
\hline Perro & LM & AMP & AmDiáfisis & AMD \\
\hline Tibia distal & - & - & - & 20 \\
\hline
\end{tabular}


la muestra sí se han reconocido marcas de roído y perforaciones, que se interpretan como un indicio de la plena domesticación e integración del perro en la vida del poblado porque probablemente las causaron estos cánidos tras el cocinado y consumo humano.

A pesar de que la cantidad de restos recuperada es escasa (tablas 7 y 8), se aprecia cierta preponderancia en el número de restos (NR) de los suidos, el bovino y el ciervo. En relación con el peso predominan el bovino y los équidos, seguidos por los ciervos y los suidos en la misma proporción, ya que se han omitido los restos de astas (no aportan carne y además pudieron haber sido recogidos tras el desmogue). Dada la muestra con que se cuenta, y que el NMI de grandes bóvidos, équidos, ciervo y suidos es prácticamente el mismo, esta diferencia entre el número de restos y la representatividad en peso es difícilmente interpretable, aunque en general se puede atribuir a estos grandes animales gran relevancia en la alimentación (la mayor parte de los huesos parece haber sido sometida a cocción). Por el contrario los ovicaprinos están escasamente representados en La Sierrecilla, aunque su uso está mejor documentado en otros yacimientos de esta zona (Castaños 1991). En cualquier caso no resulta extraño el predominio del cerdo sobre el ovicaprino en un ecosistema rico en encinares.

Es interesante sin embargo constatar la relativa abundancia de los ungulados salvajes, salvando los problemas antes mencionados de clasificación taxonómica. Parece que la caza era una actividad aún relevante, teniendo al uro y al ciervo como objetos habituales. Por lo tanto, los resultados tras los análisis de las arqueofaunas de La Sierrecilla pueden concordar bien con una

Tabla 7. Número de restos (NR), número mínimo de individuos (NMI) y porcentajes.

\begin{tabular}{|c|c|c|c|c|}
\cline { 2 - 5 } \multicolumn{1}{c|}{} & NR & $\%$ & NMI & $\%$ \\
\hline Bóvido & 38 & 9,13461538 & 3 & 20 \\
\hline Équido & 28 & 6,73076923 & 3 & 13,3333333 \\
\hline Ciervo & 37 & 8,89423077 & 3 & 20 \\
\hline Suido & 42 & 10,0961538 & 1 & 6,66666667 \\
\hline Ovicápridos & 11 & 2,64423077 & 1 & 6,66666667 \\
\hline Oveja & 1 & 0,24038462 & 1 & 6,66666667 \\
\hline Perro & 1 & 0,24038462 & 1 & 6,66666667 \\
\hline Corzo & 1 & 0,24038462 & & 100 \\
\hline Indeterminados & 257 & 61,7788462 & 15 & \\
\hline TOTAL & 416 & 100 & & \\
\hline
\end{tabular}

Tabla 8. Número de restos (NR) menos las astas y peso en gramos.

\begin{tabular}{|c|c|c|c|}
\cline { 2 - 4 } \multicolumn{1}{c|}{} & NR & W (gr) & W \% \\
\hline Bóvido & 38 & 3.819 & 33,7695641 \\
\hline Équido & 28 & 2.653 & 23,4591918 \\
\hline Ciervo & 24 & 796 & 7,03864179 \\
\hline Suido & 42 & 873 & 7,71951543 \\
\hline Ovicápridos & 11 & 79 & 0,69855867 \\
\hline Oveja & 1 & 12 & 0,10611018 \\
\hline Perro & 1 & 5 & 0,04421257 \\
\hline Corzo & 0 & 0 & 0 \\
\hline Indeterminados & 257 & 3.072 & 27,1642055 \\
\hline TOTAL & 403 & 11.309 & 100 \\
\hline
\end{tabular}


economía agrícola y de pastoreo (Uerpman 1978), complementada por el aprovechamiento de fauna salvaje.

\section{Material de construcción}

Aunque en diversos tramos de la zanja 2 aparece algún fragmento de material de construcción (con un máximo de 6 en el tramo 10), su presencia más significativa se da lógicamente en la cata $4 \times 4$. Se trata de restos muy interesantes por su buen estado de conservación: se aprecian en ellos los negativos perfectos de los entramados de cañas que formaban las viviendas. En algunos casos hay improntas de otros elementos vegetales. No se ha podido realizar, sin embargo, ningún análisis en este sentido.

Muchos fragmentos de material constructivo aparecen quemados, con un patrón según el cual arden primero las superficies internas, y en caso de que el fuego sea de alta intensidad o generalizado, parecen quemarse las superficies externas. Esto es así porque son los entramados vegetales los que sucumben al fuego, probablemente de forma lenta y sin contacto con el aire durante un período de tiempo relativamente prolongado, porque el barro lo evita.

La concentración más importante de material de construcción se da en las uuee 4 (10720 gr) y 6 (9630 gr). Además la ue 5 (2850 gr), definida prácticamente por este aspecto, ha de considerarse unida a la ue 4 .

\section{Metalurgia $^{4}$}

La ausencia de datos sobre metalurgia es una constante en las vegas del Guadiana, tanto en el Calcolítico como en la Edad del Bronce, en la que hasta recientemente no se había documentado ninguna evidencia de su producción (Pavón 1998: 75). La excepción eran algunos restos de escorias que Hurtado y Hunt (1999: 265) reconocieron en la fase I de la Solana, ya en momentos considerados propios de un periodo transicional entre el Calcolítico y la Edad del Bronce.

En La Sierrecilla se han recuperado fragmentos de 5 recipientes relacionados con la metalurgia: 4 lingoteras (SIE/2005/M/1/1/4, SIE/2005/M/7/4/1, SIE/2005/ $\mathrm{M} / 7 / 4 / 2$, SIE/2005/M/7/4/5) y una posible vasija de reducción (SIE/2005/M/7/4/3). El SIE/2005/M/7/4/1 apareció roto, pero ha sido posible reconstruir al menos un extremo completo de la lingotera (lámina 1). A

4. Se encuentra en curso un estudio específico sobre la metalurgia de La Sierrecilla. simple vista se observaban en algunos de estos fragmentos escorificaciones de cobre.

Los análisis llevados a cabo por Salvador Rovira en el Museo Arqueológico Nacional han confirmado la presencia de cobre-arsénico (Cu-As) en tres fragmentos: SIE/2005/M/7/4/1,SIE/2005/M/1/1/4,ySIE/2005/M/7/4/3 (dos lingoteras y la posible vasija de reducción). El resto no han dado trazas de metalurgia, circunstancia que también se ha documentado en algunas piezas de funcionalidad similar de La Pijotilla, que no mostraban escorificaciones (Hurtado y Hunt 1999: 265).

Tanto la morfología de los fragmentos (lingoteras), cuyos paralelos más claros están en Cabezo Juré, Huelva (Nocete et alii 2004), como la aleación detectada son comunes en el Calcolítico. Por sus características formales, las lingoteras remiten a un período amplio de tiempo, que alcanzaría el Bronce antiguo. En La Sierrecilla puede matizarse esta cronología en función de los materiales arqueológicos recuperados, situándola en la primera mitad del III milenio.

Además se ha documentado un fragmento de tobera (SIE/2005/9/1/13) identificado por Salvador Rovira. Los análisis para determinar la presencia de mineral en ella no han dado resultado, una situación que de un modo $\mathrm{u}$ otro también se refleja en el conjunto del Suroeste peninsular (Hunt y Hurtado 1999: 295-296), donde las toberas documentadas no abundan. Se ha descrito una entre los materiales calcolíticos del yacimiento de São Brás 1, aunque las escorificaciones en este caso parecen corresponderse claramente con hierro (Soares et alii 1994: 171-172). Los mismos problemas plantea un fragmento procedente del área de fundición de cobre identificada en el Castelo de Corte de João Marques (Gonçalves 1989: 166). Pese a la dificultad existente en la identificación de estas piezas, también se conocen toberas relacionadas con los hornos de reducción de mineral en Cabezo Juré (Nocete et alii 2004: 283), que tipológicamente son muy similares al ejemplar de La Sierrecilla.

Estos vestigios permiten suponer que al menos una parte del proceso de producción metalúrgica se llevaba a cabo dentro del asentamiento y en un ambiente doméstico, lo que ayuda a caracterizar la pauta de producción dentro de un esquema socio-económico específico. En concreto, los elementos recuperados nos llevan al proceso final, en el que se produce la reducción del mineral y su transformación definitiva. Su concentración en áreas domésticas, a falta de una intervención sistemática en otras áreas del poblado, permitiría pensar que se trata de producciones orientadas al consumo local, más que a una cierta especialización en la producción del metal. Esto no excluye la posibilidad, por otro lado, de que una vez producidos los lingotes de 
cobre éstos se movieran a través de redes de intercambio a lo largo de la cuenca del Guadiana.

De hecho, aunque la gran concentración de restos detectados en tan escasa superficie y la presencia positiva de metalurgia podrían indicar la existencia de vetas de relativa importancia en el entorno de La Sierrecilla, los indicios de mineralizaciones de cobre en la zona son realmente escasos; únicamente se han detectado algunos afloramientos superficiales de azurita o malaquita en la zona de Oliva de Mérida $^{5}$, que podrían haber sido beneficiados durante el Calcolítico (Enríquez 2003: 86), junto a otras mineralizaciones más alejadas en la comarca de La Serena o Logrosán (Meredith 1998: 78). Si efectivamente desde La Sierrecilla se estaban explotando estos pequeños afloramientos estaríamos ante un patrón distinto de lo conocido hasta ahora, pues las evidencias más notables de minería calcolítica documentadas hasta el momento se encuentran, dentro de la cuenca del Guadiana, en la zona del sur de Badajoz, donde los filones cuprosos y otros recursos mineros son significativos (Enríquez 1990: 80-83) y parece probada su explotación real durante la prehistoria.

\section{INTERPRETACIÓN}

A falta de dataciones absolutas, los paralelos en la cultura material y la estratigrafía son los argumentos fundamentales para asignar cronología a La Sierrecilla, aunque en términos de localización también guarda una relación estrecha con los patrones generales dados para este momento (ver más abajo).

Los materiales arqueológicos recuperados, elemento de datación relativa más sólido de que se dispone, indican que la vida útil de La Sierrecilla se desarrolló durante la primera mitad del III milenio cal BC. La cerámica está dominada por los platos de borde engrosado y almendrado como elementos más característicos del registro material, cuya tipología y sus proporciones entran dentro de un modelo arquetípico de esta época (Enríquez 1990), tanto en la cuenca extremeña del Guadiana como en su parte portuguesa. Algunos rasgos, como las cerámicas decoradas, pueden ponerse en relación con las dataciones de la comentada cabaña de Cabrerizas y por tanto en un momento de mediados del III milenio cal BC (González Cordero et alii 1991; Bueno et alii 2000: 222). Hay que señalar, en cualquier caso, la presencia de algunos elementos carenados que tradicionalmente se vienen considerando

5. Base de datos de indicios de mineralizaciones del SIGEO de la Junta de Extremadura. como los indicadores de un poblamiento del IV milenio cal $\mathrm{BC}$, elementos residuales interpretados como pervivencia de algunos rasgos culturales y materiales de momentos previos (Enríquez 1995: 29; 2003: 78). Sin embargo no es rara su presencia en la parte portuguesa (Gonçalves 1995) en momentos más avanzados de la secuencia del Calcolítico. No parece, por tanto, que sea posible rastrear el origen de la ocupación en La Sierrecilla en momentos anteriores al III milenio cal BC. Parece que su establecimiento comienza en un periodo en el que es patente la diversificación del patrón de asentamiento en toda la vega del Guadiana.

El primer nivel en todo el yacimiento es la ue 1, de relleno. La ue 2, también extensible a todo el yacimiento, aparece en la zona de juegos infantiles relacionada con el hábitat (cerámica aparentemente in situ y estructura en piedra). Pero las posibilidades de interpretación de la ue 2 , incluso a partir de la cata $4 \times 4$, son escasas. En general parece que existen varios niveles de ocupación, de los que la ue 2 sería el último, y, quizá en la cata al menos, podría representar una fase de abandono. Esto se deduce solamente por exclusión: el nivel inferior a este, la ue 4, marca una importante discontinuidad, reconocible, en primer lugar, en que la densidad de los restos recuperados, tanto en lo que se refiere a cerámica como a industria lítica, fauna y material de construcción, crece extraordinariamente. Además existen diferencias cualitativas, que se observan claramente en la presencia de carenas, decoración cerámica y proporciones tipológicas de las cerámicas.

La ue 4 sería por tanto el primer nivel de hábitat reconocible, que continúa (reconstruyendo la secuencia a la inversa) hasta la roca madre, donde incluso se ha documentado la mitad de una vivienda (actividad 1), con niveles muy potentes de ceniza y una interesante cerámica asociada. La intervención no ha permitido delimitar esta actividad en su totalidad.

En la ue 4 se produce además un hecho diferencial fundamental, reflejado en la presencia de elementos relacionados con la metalurgia. Dada la pequeña cantidad de terreno intervenida se puede proponer que la actividad metalúrgica en este poblado fue bastante relevante, o bien que la cata $4 \times 4$ ha coincidido con un área funcional específica. En general esta cuestión es problemática porque se encuentran dificultades para identificar con precisión las áreas de transformación metalúrgica de los poblados excavados. Son destacables los recientes datos obtenidos en el yacimiento de San Blas (Cheles), que han permitido identificar una zona exterior al poblado con hornos, algunos indicadores de producción metalúrgica y productos finales que revelarían la presencia de un lugar con relativa especialización (Hurtado 
2004: 106). En cualquier caso en esta pequeña área de La Sierrecilla se han documentado al menos dos fases del proceso metalúrgico (a través de la vasija de reducción y las lingoteras), algo relativamente singular en el panorama general del Calcolítico extremeño. Sin embargo sumado a los datos que proceden de otros yacimientos como Cabezo Juré, permiten ir reconociendo los procesos técnicos y metalúrgicos del Suroeste peninsular en un contexto más general, que comprende otras áreas peninsulares (Nocete et alii 2005: 293).

Como se dijo en la introducción, la aportación de La Sierrecilla al panorama del análisis de la metalurgia de la Cuenca Media del Guadiana viene a plantear una situación novedosa dentro de la producción metalúrgica prehistórica conocida en este área por dos razones: parece documentarse la práctica de la metalurgia fuera de las áreas mineras por excelencia del sur del Guadiana, y por tanto la probable explotación de vetas de reducido tamaño, y además se documenta dentro de un poblado de escasa superficie. Ambos factores corroboran la idea de que la metalurgia se desarrolló en un ambiente de relativo conservadurismo, posiblemente no especializado, en el que aquella se incorporó como un aspecto más de un sistema de explotación económica determinado por un variado conjunto de estrategias. Pese a la ausencia de datos de carácter paleoambiental resultan fundamentales los datos derivados del estudio de la fauna, en los que se observa cierta complementariedad de la producción y la explotación de recursos silvestres. Este modelo podría tomarse tentativamente como referencia para ser contrastada en otros yacimientos de la cuenca del Guadiana, bajo la hipótesis de una producción metalúrgica relativamente temprana y ligada a una aparente débil especialización social.

En la Cuenca Media del Guadiana los yacimientos calcolíticos con evidencias de transformación y producción metalúrgica son muy escasos, y no se poseen aún dataciones definitivas de contextos de transformación o producción. Aparte de los datos ya aportados por los trabajos más recientes sobre el tema (Hurtado y Hunt 1999), que siguen resultando escasos, en los últimos años se ha documentado el uso de crisoles de fundición en el yacimiento de Castillejos I (Cerrillo et alii e.p.), y tal vez dentro de este panorama pudieran incluirse las escorias de cobre y los crisoles recogidos durante la excavación de estructuras calcolíticas en el casco urbano de Zafra (Gutiérrez 2005), al igual que las de La Sierrecilla, aparentemente dentro de estructuras de habitación. En el caso de Los Castillejos I de Fuente de Cantos, la datación absoluta disponible para la última fase de ocupación (Cerrillo et alii e.p.), obtenida sobre muestras de vida corta, la sitúa a mediados del III milenio cal BC (3990 $\pm 40 \mathrm{BP})$, lo que plantea una fecha post quem al uso de los crisoles recogidos sin contexto durante las campañas de excavación de los años 80. La existencia de escorias de cobre en el yacimiento de Zafra también parece sostener una cronología de comienzos del III milenio para la ocupación calcolítica, según se desprende de los resultados de excavación publicados (Gutiérrez 2005).

De cualquier forma, esa cronología antigua de la metalurgia calcolítica del Suroeste peninsular se apoya también en los resultados recientes obtenidos en otras áreas de la misma región, donde las dataciones efectuadas en contextos con producción metalúrgica clara remiten a un inicio de la producción en épocas tempranas: inicios del III milenio cal BC (Nocete et alii 2005: 227) en el caso de las fases I y II de Cabezo Juré, pero también puede argumentarse una práctica relativamente temprana a partir de la estratigrafía y las dataciones de finales del IV milenio cal BC del poblado de Sala 1 (Gonçalves 1988). Estas cronologías centradas en el primer tramo del III milenio BC contextualizan bien, según los datos disponibles, la actividad metalúrgica de La Sierrecilla.

Esta propuesta guarda además relación con la dinámica de poblamiento que se puede observar en el entorno lejano del poblado. En el término municipal de Santa Amalia no se contaba con núcleos de poblamiento calcolítico hasta la actualidad, por lo que no es posible hablar de una manera nítida de la vertebración territorial a escala local. No obstante, se conocen bastante mejor las pautas de poblamiento del conjunto de las márgenes del Guadiana, una de las áreas con mayor concentración de hábitats de finales del IV y III milenio en el conjunto de Extremadura.

Los trabajos de prospección realizados en el entorno del Guadiana por J.J. Enríquez (1990; 2003) permiten una aproximación bastante fiel a la evolución del modelo de poblamiento calcolítico de las márgenes del Guadiana, que se completa con algunos poblados recientemente documentados (Heras y Cerrillo 2006). Pese al gran número de yacimientos identificados en superficie hay que hacer notar que aún no se dispone de suficiente información sobre características estratigráficas y paleoambientales, que darían otra dimensión cronológica y socio-económica a la interpretación de la Prehistoria Reciente del área que nos ocupa.

En todo este amplio territorio los poblados con materiales más antiguos remiten a finales del IV milenio cal BC, indicando un sistema de poblamiento constante y bien caracterizado en todas las márgenes del Guadiana, que se desarrollaría probablemente en tierras de alta potencialidad agrícola y ligado a la proximidad de 
cauces de agua (Enríquez 1996). Su documentación es cada vez más consistente. En el caso del entorno de Mérida, este poblamiento está comprobado en los yacimientos de Araya, Camino de Meriendas, La Piedra y Pozo de la Cañada, en términos municipales próximos a Santa Amalia, y de manera especial en algunas zonas del casco urbano de Mérida.

A comienzos del III milenio se observan dos tendencias específicas en el modelo de poblamiento de este sector: de un lado el incremento de los poblados conocidos que se extienden en nuevas áreas; del otro, la ubicación de poblados con clara vocación estratégica. El patrón de ubicación del poblamiento, diagnosticado a partir de materiales de superficie, parece sugerir que se situaban lejos de áreas potencialmente inundables, pero próximas a cauces de agua de cierta entidad. La vocación estratégica de los poblados viene determinada por su ubicación en áreas de vados (Enríquez 2003: 79-80), que pudieran controlar algunos de los pasos del Guadiana, pero también en áreas determinadas por condiciones de dominio visual sobre el entorno (Heras y Cerrillo 2006), generalmente cerros ligeramente aislados desde los que se divisa gran parte de las llanuras del Guadiana. A ese esquema pertenecería precisamente el yacimiento de La Sierrecilla, junto a otros documentados como La China (Guareña), Valdefuentes (Don Benito) o más al sur el Morro de la Oliva. Únicamente en el yacimiento de La Palacina fue posible documentar estructuras defensivas (Enríquez 1990) que aseguraran la fortificación del hábitat. En el caso de La Sierrecilla ya se ha comentado la imposibilidad de decidir sobre la existencia de estas estructuras a partir del mero reconocimiento superficial.

Es destacable que todos ellos son lugares con un mismo patrón de localización: se encuentran en zonas elevadas y al pie de afluentes del Guadiana. La similaridad con La Sierrecilla es clara. Sin embargo la inexistencia de datos estratigráficos en la mayoría de estos poblados impide establecer una correspondencia afinada.

En cualquier caso sí se ha definido un patrón regular de localización de yacimientos calcolíticos en esta zona (Enríquez 1990 y 1995) con dos situaciones básicas posibles: sin aparente vocación estratégica (en llano o sobre suaves lomas) o con una patente posición de control del paisaje (en cerros aislados con o sin estructuras defensivas). La ubicación de La Sierrecilla responde claramente a una necesidad de control territorial, con el factor añadido de estar flanqueado por un curso de agua (río Búrdalo), que crea una vega fértil con condiciones óptimas para el cultivo. Estaría probablemente incluido en un sistema de poblamiento complementario que integraría diferentes sectores paisajísticos y por tanto recursos. De hecho a finales del IV milenio y principios del III milenio parece que se produce un incremento y expansión del poblamiento tanto en llano como fortificado, con nuevos modelos de ocupación hasta entonces inéditos que incluyen zonas muy fértiles y zonas muy elevadas y abruptas (Hurtado 1995). Este sistema está aún por definir en el entorno local que se ha tratado.

\section{BIBLIOGRAFÍA}

BUENO, P.; GONZÁLEZ CORDERO, A. y ROVIRA LLORENS, S. (2000): “Áreas de habitación y sepulturas de falsa cúpula en la cuenca extremeña del Tajo. Acerca del poblado con necrópolis del Canchal en Jaraíz de la Vera (Cáceres)", en J. Jiménez Ávila y J.J. Enríquez Navascués (eds), El megalitismo en Extremadura (Homenaje a Elías Diéguez Luengo): 209-242. Extremadura Arqueológica VIII.

BUENO, P.; BARROSO, R. yBALBÍN, R. DE(2002-2003): "Las primeras producciones metálicas en la cuenca interior del Tajo: Cáceres y Toledo", Estudos PréHistóricos X-XI: 87-106.

CASTAÑOS, P.Ma (1991): “Animales domésticos y salvajes en Extremadura. Origen y evolución", Revista de Estudios Extremeños XLVII (I): 9-66.

- (1998): "Estudio de la fauna del cerro I de Los Castillejos (Fuente de Cantos, Badajoz)", Norba 14 (1994): 11-45.

CERRILLO CUENCA, E. (2005): Los primeros grupos neolíticos de la cuenca extremeña del Tajo. Oxford, British Archaeological Reports, S1393.

CERRILLO CUENCA, E.; FERNÁNDEZ CORRALES, J. M.; HERAS MORA, F. J.; PRADA GALLARDO, A. y LÓPEZ SÁEZ, J .A. (ep): “Cambios y permanencias en el entorno de Castillejos, de finales del Neolítico a comienzos de la Edad del Bronce", $3^{\circ}$ coloquio transformações e mudanzas no III ${ }^{\circ}$ milenio no centro e sul de Portugal. Cascais.

ENRÍQUEZ NAVASCUÉS, J.J. (1988): “Informe sobre las excavaciones llevadas a cabo en el yacimiento de Araya (Mérida, Badajoz). 1983 y 1984", Extremadura Arqueológica I: 14-25.

- (1990): El Calcolítico o Edad del Cobre de la cuenca extremeña del Guadiana. Badajoz, Publicaciones del Museo de Badajoz 2.

- (1995): "Del Paleolítico a la Edad de Bronce", Extremadura arqueológica 4: 13-34.

- (1996): "Vestigios neolíticos de la Cuenca Media del Guadiana (provincia de Badajoz)", I Congrés del Neolític a la Península Ibérica: 689-696. Rubricatum 1 (2). 
- (2003): Prehistoria de Mérida (Cazadores, campesinos, jefes, aristócratas y siervos anteriores a los romanos. Mérida, Cuadernos emeritenses 23.

ESTRADA, F. J.; ONTALBA SALAMANCA, M. A.; RESPALDIZA GALISTEO, M. A.; PÉREZ QUESADA, P. y HURTADO PÉREZ, V. M. (1999): "Técnicas Nucleares Aplicadas al Estudio de Cerámicas del Calcolítico Extremeño", Actas del I Congreso Nacional de Arqueometria. Arqueologia y Arqueometria. Congreso Nacional de Arqueometría 1: 77-88. Granada. Universidad de Granada.

GÓMEZ RAMOS, P.; MONTERO RUIZ, I. y ROVIRA LLORENS, S. (1998): "Metalurgia protohistórica extremeña en el marco del Suroeste Peninsular", en A. Rodríguez Díaz (coord.), Extremadura Protohistórica: Paleoambiente, Economía y Poblamiento: 97-17. Cáceres.

GONZÁLEZ CORDERO, A.; CASTILLO CASTILLO, J. y HERNÁNDEZ HERNÁNDEZ, M. (1991): “La secuencia estratigráfica en los yacimientos calcolíticos del área de Plasenzuela (Cáceres)", en Extremadura Arqueológica II. I Jornadas de Prehistoria y Arqueología en Extremadura (1986-1990): 11-26. Salamanca.

GONÇALVES, V.S. (1988): “O povoado pré-histórico da Sala $n^{\circ} 1$ (Pedrogão, Vidigueira): notas sobre a campanha 1(88)", Portugália. Série, 8-9: 7-16.

- (1989): Megalitismo e metalurgia no alto Algarve oriental. Uma aproximaçao integrada. Vol. I. Lisboa, Estudos e memorias, instituto nacional de investigaçao cientifica.

- (1995): Sítios, "Horizontes" e Artefactos. Leituras críticas de realidades perdidas. Cascais, Câmara Municipal de Cascais.

GUTIÉRREZ MORAGA, A. (2005): “La transición del Neolítico al Calcolítico en Zafra", Cuadernos de Çafra. Estudios sobre la Historia de Zafra y el Estado de Feria, III: 21-36.

HERAS, J. y CERRILLO CUENCA, E. (2006): "Paisaje y dinámica cultural de la Prehistoria Reciente en el Guadiana Medio", IV Congresso de Arqueología Peninsular. De Epipaleolitico ao Calcolitico na Península Ibérica: 279-291. Faro.

HURTADO, V. (1995): “Interpretación sobre la dinámica cultural en la Cuenca Media del Guadiana (IV-II milenio a.n.e.)", Extremadura Arqueológica 5: 53-80.

- (2003): "Fosos y fortificaciones entre el Guadiana y el Guadalquivir en el III milenio a.C.: evidencias del registro arqueológico", en S. Oliveira Jorge (coord.), Recintos murados da Pré-Historia Recente: 251-268. Porto-Coimbra.

- (2004): "San Blas. The discovery of a large chalcolithic settlement by the Guadiana River", Journal of Iberian Archaeology: 93-106.
HURTADO, V. y AMORES, F. (1982): "Estudio de relaciones culturales entre el sudeste francés y La Pijotilla (Badajoz) en el Calcolítico: las pastillas repujadas y el Campaniforme cordado", Habis 13: 189-211.

HURTADO, V. y HUNT, M. (1999): "Extremadura", en G. Delibes y I. Montero (eds.) Las primeras culturas metalúrgicas de la Península Ibérica: 241-274. Madrid.

LÓPEZ-ROMERO, E. (2005): Arqueología del Paisaje y megalitismo en el centro-oeste peninsular: evolución de las pautas de poblamiento en torno a la cuenca del río Sever (España-Potugal), Tesis Doctoral inédita, Madrid, Universidad Autónoma de Madrid.

MARTÍN DE LA CRUZ, J.C. (1986): Papa Uvas II. Aljaraque. Huelva. Campañas de 1981 a 1983. Madrid, Ministerio de Cultura.

- (1994): El tránsito del Neolítico al Calcolítico en el litoral del sur-oeste peninsular. Madrid, Ministerio de Cultura.

MEREDITH, C. (1998): "El factor minero: el caso del estaño y el poblado de Logrosán (Cáceres)", en A. Rodríguez Díaz (coord.), Extremadura Protohistórica: Paleoambiente, Economía y Poblamiento: 73-96. Cáceres.

NOCETE CALVO, F.; LIZCANO PRESTEL, R.; NIETO LUJÁN, J. M.; ÁLEX TUR, E.; INACIO FRANCO, N. M.; BAYONA, M. R.; DELGADO HUERTAS, A.; ORIHUELA PARRALES, A. y LINARES CATELA, J. A. (2004): "La ordenación espacio-temporal del registro arqueológico de Cabezo Juré", en F. Nocete Calvo (coord), ODIEL. Proyecto de Investigación Arqueológica para el Análisis del Origen de la Desigualdad Social en el Suroeste de la Península Ibérica: 129-232. Arqueología Monografías 19. Sevilla.

PAVÓN, I. (1998): El Cerro del Castillo de Alange. Intervenciones arqueológicas (1993). Memorias de Arqueología Extremeña 1.

RAPOSO, L. y SILVA, E.J.L. da (1984): “O Languedocense: ensaio de caracterizaçao morfotécnica e tipológica", O Arqueólogo Português, Serie IV, 2: 87-166.

SOARES, A. M.; ARAUJO, M. DE F. y CABRAL, J. P. (1994): "Vestígios da práctica de metalurgia em povoados calcolíticos da Bacia do Guadiana, entre o Ardila e o Chança”, en J. Campos, J. Pérez y F. Gómez (eds.), Arqueologia en el entorno del Bajo Guadiana: 165-200. Huelva.

UERPMAN, H.P. (1978): "Informe sobre los restos faunísticos de la Peña de los Gitanos", en A. Arribas y F. Molina (eds.), El poblado de los Castillejos en las peñas de los Gitanos (Montefrío, Granada): 153-168. Granada, Cuadernos de Prehistoria de la Universidad de Granada 3. 


\section{AGRADECIMIENTOS}

A Eduardo Moreno García, Javier Heras y Carmen Pérez Maestro, Jose Ramón Alvarado Mariscal y Belén Alonso Gómez, y Juan Vicent García.

De Tragsa a Antonio Jimeno Ramírez y Valentín Simeonov Vasilev.

A Ma Carmen Barroso Mateos y Antonio el Guinda, vecinos de Santa Amalia.
Por la información arqueológica y petrológica a Pedro Aguayo de Hoyos, Elías López-Romero González de la Aleja y Esteban Moreno Guerrero.

Por la ayuda prestada en la identificación de las arqueofaunas a José Antonio Riquelme Cantal.

Por la ayuda con Autocad y Arcview a Elías LópezRomero González de la Aleja y Carlos Fernández Freire. 